\title{
EXPERIMENTAL EVIDENCE OF THE INFLUENCE OF PLASTICITY AND SURFACE- ROUGHNESS ON FATIGUE CRACK-CLOSURE PHENOMENON IN VACUUM
}

\section{C. Lafarie-Frenot and C. Gasc} Laboratoire de Mécanique et de Physique des Matériaux, ERA 123 du CNRS, ENSMA. Rue
Guillaume VII, 86034, Poitiers Cedex. France

ABSTRACT

Fatigue tests with a decreasing stress intensity amplitude down to the threshold were performed in vacuum on CT specimens in four age-hardening alloys, and for two values of load ratio. Crack closure measurements (by compliance and potential drop methods) were made at threshold and compared with the aspect of the crack on the side of the specimen. A correlation is made between the plastic deformation aspect spacing measured between the edges of the crack at zero load. These results spacio measures history during the test, which must be taken in account to understand the localization of crack closure and the length of crack over which it was observed.

$$
\text { KEYWORDS }
$$

Fatigue. Threshold. Vacuum. Crack closure.

\section{INTRODUCTION}

The crack closure model, first developed by Elber (1970), attempts to explain spectrum loading fatigue crack growth in terms of the effective stress intensity range, $\Delta$ Keff for which the crack is open. Crack closure was first considered to arise from the fact that, during crack advance, material is plastically strained at the crack tip and, due to the restraint of surrounding elastic material on this residual stretch, some closure of the crack occurs above the minimum load of the fatigue cycle. Recent studies pointed out that a second mechanism, termed roughness-induced crack closure, (Minakawa, 1981), arises in situations where the size-scale of the fracture surface roughness is comparable to crack tip displacements and where significant Mode II displacements exist, e.g. at near threshold levels (Davidson, 1981). Models for fatigue crack closure based on surface roughness (Suresh, 1982) and residual strain (Granville sewell, proposed that would permit to calculate $\Delta k$ eff in some simple configurations in vacuum. The purpose of the pristory and roughness configuration all along state the infuence of loading history and roughn 
EXPERIMENTAL RESULTS

\section{Experimental Conditions}

Fatigue tests were carried out on CT specimens of $75 \mathrm{~mm}$ width and $12 \mathrm{~mm}$ thickness, using an Instron electro-hydraulic fatigue testing machine equipped with a vacuum chamber in which a pressure less than $10^{-3} \mathrm{~Pa}$ can be obtained. A vacuum environment was chasen to avoid any oxyde-induced crack closure. The crack propagation was obtained by a series of load drops down to the threshold at a constant load ratio (R) value, an frequency of $40 \mathrm{~Hz}$. In fig.l is schematically shown the wake of residual strain left behind, as the crack grows. Two values of load ratio were investigated in four aged $R=0.5$ and an industrial Aluminium al loy (7075 Al alloy) in four aged hardening conditions was chosen because of the very different crack surfaces In

TABLE I - Age-hardening conditions properties

\begin{tabular}{|c|c|c|c|c|}
\hline $\begin{array}{l}\text { Symbol used in this } \\
\text { study }\end{array}$ & $\bar{A}$ & $\bar{B}$ & $\mathrm{C}$ & $\bar{D}$ \\
\hline Heat Treatment & $\begin{array}{l}\text { T } 351 \\
\text { Underaged }\end{array}$ & $\begin{array}{l}\text { T } 651 \\
\text { Peak-aged }\end{array}$ & $\begin{array}{l}\text { T } 7351 \\
\text { Over-aged }\end{array}$ & $\begin{array}{l}24 \mathrm{~h} \text { at } 200 \\
\text { Hyperoveraged }\end{array}$ \\
\hline \multirow[t]{2}{*}{$\begin{array}{l}\text { Hardening } \\
\text { precipitation }\end{array}$} & $\begin{array}{l}\text { GP zones }+M ' \\
\text { Shearable }\end{array}$ & $\begin{array}{l}M^{\prime}\left(+M+T^{\prime}\right) \\
\text { Shearable }\end{array}$ & \multirow{2}{*}{$\begin{array}{l}M+T^{\prime} \\
\text { Partially } \\
\text { shearable } \\
\text { Semi- } \\
\text { coherent }\end{array}$} & $\begin{array}{l}\text { M } \\
\text { Unshearable }\end{array}$ \\
\hline & Coherent & Coherent & & Incoherent \\
\hline
\end{tabular}

When a crack propagation of a few $10^{-8} \mathrm{~mm} /$ cycle was obtained, variations of compliance (measured by a back face strain gauge) and of potential drop amplitude were recorded during the last loading-cycle using a digita oscilloscope and a $X-Y$ recorder.

The specimen was then taken of $f$ the testing machine and the crack observed with an optical microscope. A lot of microphotographs have been made along the whole crack and have permitted to

Describe and analyse the aspect of plastic zone accompanying the crack the edge of the specimen

iii. Measure the evolution of the spacing between the two edges of the crack from the notch to the tip, for a load equal to zero.

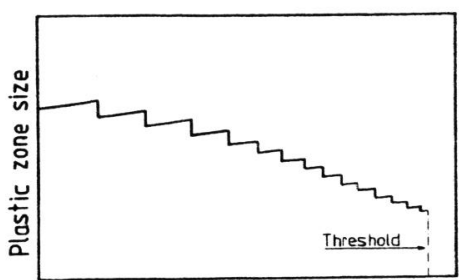

Fig.1: Schematic representation of the plastic zone size evolution along the crack during a fatigue crack propagation threshold test.
Results The crack surfaces roughis very close to the crack surfaces. This aspect thained zone alloy, the crack propagation rat (da) $d N$ ) and the load ratio (R). Two different mechanisms of plastic the tion and fracture were observed, noted respectively Type 1 for the un deraged alloy (A) and Type 11 for the hyperoveraged alloy (D), whed along the

Type I : Many straight and fine slips Tines are observed along the rack for mean crack propagation rates $\left(10^{-4} \mathrm{~mm} / \mathrm{cycle} / \mathrm{da} / \mathrm{dN} / 1 \mathrm{ke}\right.$ a $\mathrm{mm} /$ cycle). Two systems are often active an alternatively from substructure near the crack. The crack advan little asperities on one slip plane to another one when the crack growth rate decreases, the crack surfaces (Fig.2). When the crack gin decreases too, and the number of active slip systems in each gr longer. Because of the the crack length in each slip plan in the grain the crack sometimes orientation of active slip plane in the near-threshold range, grows close to the loading acrick the crack tries to finally appear many seconar attempt to quantify the crack surface find its way (fig. 3 ) roughness has been made by thly represented in fig.4. For the suresh condition, $r$ is increasing

to 0.7 for it must be noted that there exists a great scatter on the However of the non-symmetrical aspect of the sinuosities, and that the asperities (noted $h$ on fig.4) seems to be necessary for a good description of the roughness. Finally, we can say that, for the underaged Al alloy, the fracture surface roughness

i. Type II. The crack is accompanied by a wake of strained materia which is formed by little wings, looking like plastic zone created by an overload (Ranganathan, 1983). The crack often advaning little natively from a right wing to a left one, crack is always asperities (Fig.5); the mean direction of the hyper overaged remaining perpendicular to the loading axis. In the hyper advance alloy (D), where this type of plastic deformation always low and is observed, the crack surfaces roughith the crack growth rate decreases $-r$ varying from $10^{-4} \mathrm{~mm} /$ cycle to $10^{-7} \mathrm{~mm} /$ cycle.
from $10^{-4} \mathrm{mon}$

(B) and over-aged (C) Al alloys present either Type I or Type (B) and over-aged (C) Al alloys preses a mixed one (noted Type 11 plastic deformation and crack advance, I+ II) because of transitions in rates, previously observed Lafarien when such a transition from Type II to faces roughness is rapidy $R=0.1$ down to the threshold).

These results are summarized in Table II. The observations of the roughness is high, load equal to zot continuously closed, but only where the crack presents the crack is and a direction close to the loading axis (Fig.3). On the acute angles an the crack path is flat, crack closure appears localized longer crack lengths (Fig.6). 


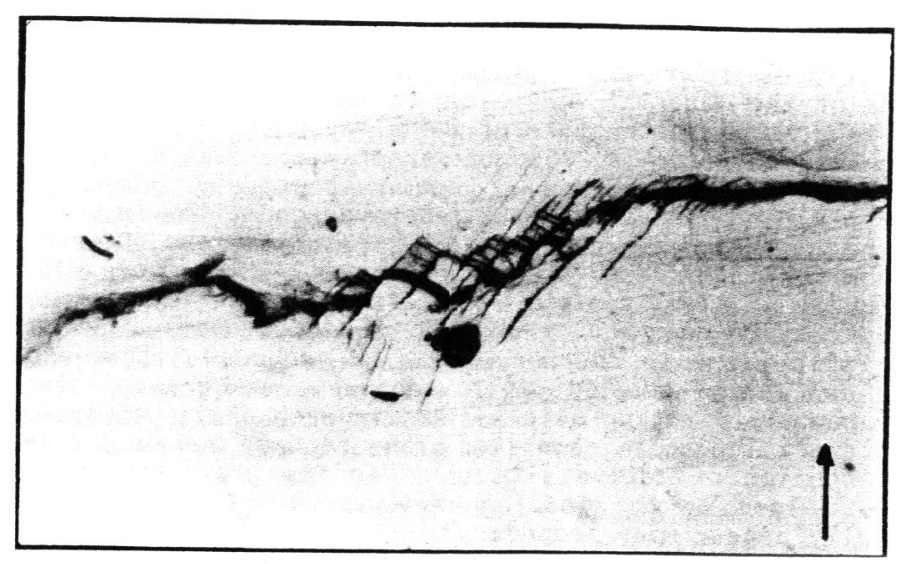

Fig.2 - Typical aspect of Type I mode of plastic deformation and fracture tes the loading axis. (Peak-aged 7075 Al alloy, $R=0.5, \mathrm{da} / \mathrm{dN}=5 \times 10^{-5} \mathrm{~mm} /$ cycle).

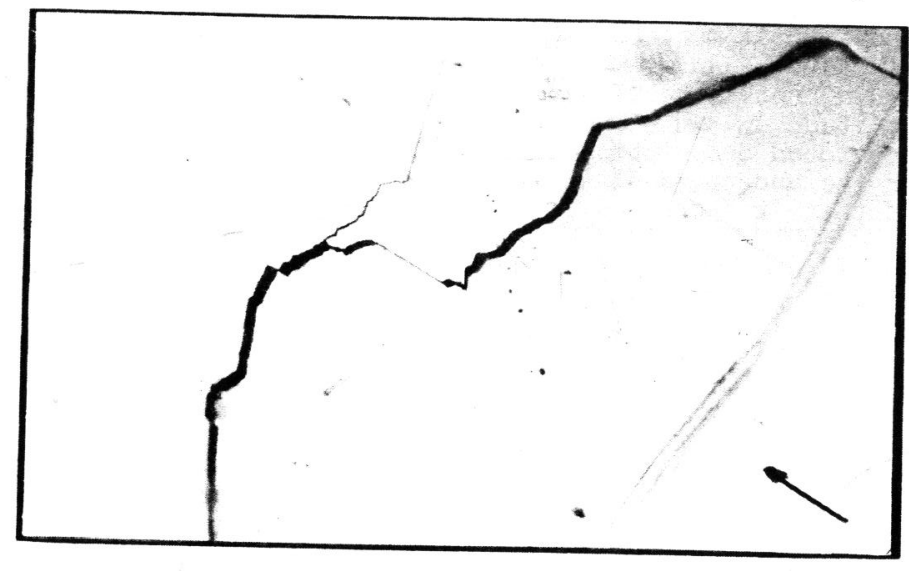

Fig.3 - Aspect of a near threshold fatigue crack in the underaged $7075 \mathrm{Al}$ alloy $\left(R=0.1, \mathrm{da} / \mathrm{dN}=10^{-7} \mathrm{mn} / \mathrm{cycle}\right)$. The arrow indicates the loading axis.

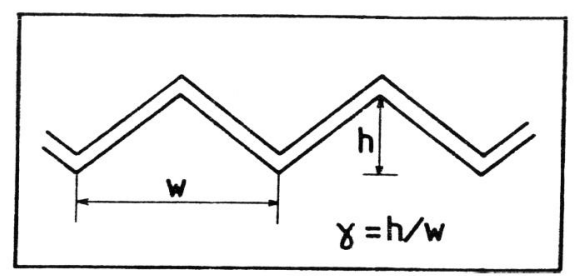

Fig. 4 - Schematic representation of a near-threshold fatigue

crack (Type I) as proposed

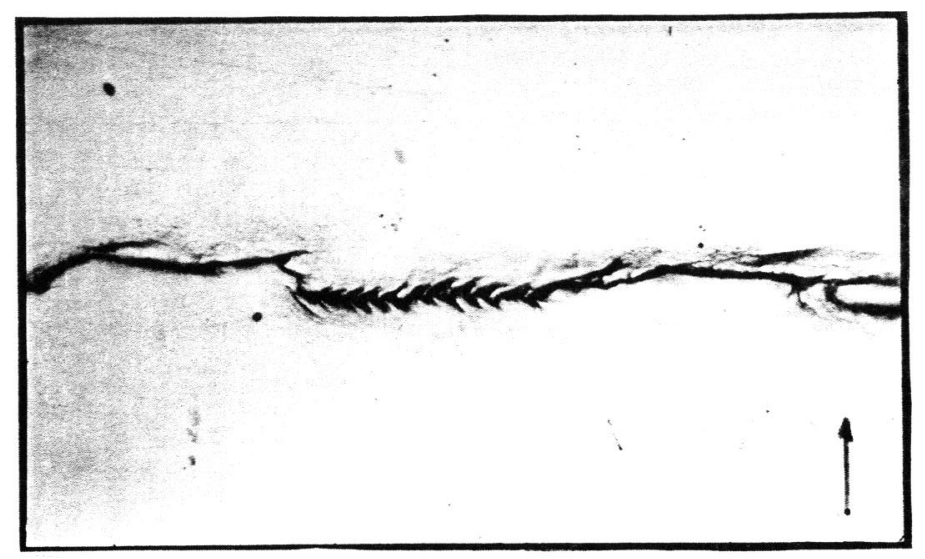

Fig.5 - Typical aspect of Type II mode of plastic deformation and fracture in the mid-range of FCGR. The arrow indicates the loading axis. (Hyper-overaged 7075 Alalloy: $R=0.5 ; \mathrm{da} / \mathrm{dN}=8 \times 10^{-5} \mathrm{~mm} /$ cycle).

TABLE II - Characteristic features of crack propagation as observed on the side of the specimen after the test from the notch to the threshold (crack surface roughness is characterized by Low, Mean, High, Very High)

\begin{tabular}{|c|c|c|c|c|c|c|c|c|}
\hline Alloy & \multicolumn{2}{|c|}{ A } & \multicolumn{2}{|c|}{ B } & \multicolumn{2}{|c|}{ C } & \multicolumn{2}{|c|}{ D } \\
\hline R ratio & 0.1 & 0.5 & 0.1 & 0.5 & 0.1 & 0.5 & 0.1 & 0.5 \\
\hline $\begin{array}{l}\text { Plastic strain } \\
\text { wake type }\end{array}$ & I & I & $\mathrm{I}+\mathrm{II}$ & $\mathrm{I}+\mathrm{II}$ & II & II & II & II \\
\hline $\begin{array}{l}\text { Crack surfaces } \\
\text { roughness }\end{array}$ & & ${ }^{\mathrm{V} . \mathrm{H}}$ & $\mathrm{M} \rightarrow$ & $M-$ & & & & L . \\
\hline $\begin{array}{c}\text { Crack growth rate } \\
\mathrm{da} / \mathrm{dN}(\mathrm{mm} / \mathrm{cycle})\end{array}$ & $y$ & $x$ & & & & & $\searrow$ & $y$ \\
\hline $\begin{array}{c}\text { Crack length } \\
\text { a }(\mathrm{mm})\end{array}$ & & & 30 & $\begin{array}{l}1 \\
26\end{array}$ & 36 & 37.5 & & \\
\hline
\end{tabular}




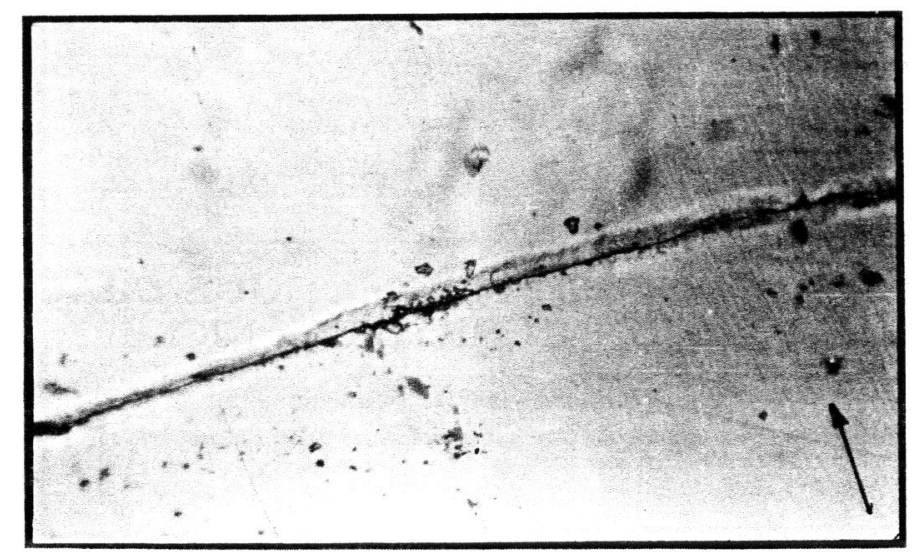

Fig. 6 - Aspect of a closed and flat fatigue crack in the hyper-overaged $7075 \mathrm{Al}$ alloy $\left(R=0.1: \mathrm{da} / \mathrm{dN}=8 \times 10^{-7} \mathrm{~mm} / \mathrm{cycle}\right)$. The arrow indicates the loading axis.

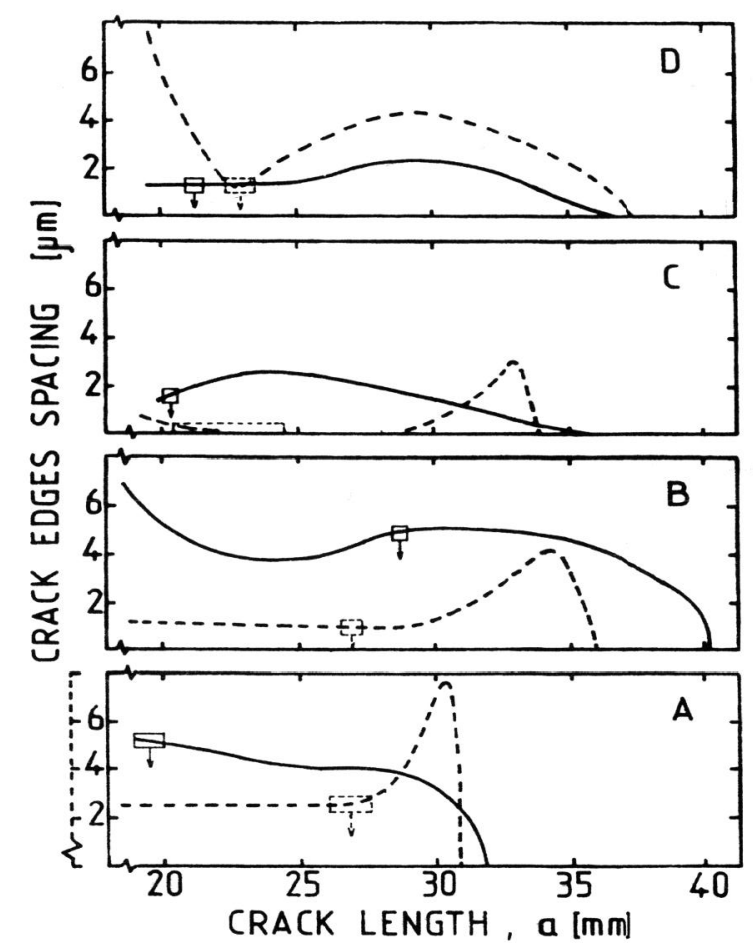

ig.7 - Average profiles of the residual spacing between the crack edges in the four aged-hardening conditions and for the two values of load ratio (Solid Tines $R=0.1$; dashed lines $R=0.5$ ). Scatter bands on the curves give the value of a* deduced ments.
On the microphotographs of the crack, measurements of the mean residual spacing spacing between its edgested the average profiles of the residual spacing in fig. the crack edges in each case of aged condition and load ratio for a between the cralues of equivalent crack length at zero load (noted $a^{*}$ ) obtained by reporting on the calibration curves (compliance a vs crack length $a$, and potential drop amplitude $\Delta V$ vs crack length a) the measured values of $\alpha$ and $\Delta V$ at zero load, are plotted with their scatter measurese curves. These values show that, for the strain gauge and the voltmeter, the crack is almost totally closed at zero load, though the crack is still observed open in the vicinity of the crack tip, particularly for $R=0.5$. In this case, an increasing residual spacing between the two crack edges is observed near the crack tip for the $B$ and $C$ conditions, whilure corresponds to the transition from type li to type i mode of far the described above. Note that the values of residual spacing obtantal overload

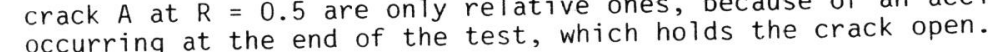

\section{DISCUSSION}

The slips observed near the crack and described as Type I, correspond to a crystimber crystallographic mode of failure, by shack growth rate. This observation is in active planes decreasing microfractographies made in in accordance with the crack surfaces roughthese alloys (Lafarie-frenot, ness is very important and is loading axis; this localization the crack growth direction is close to the loading axis ; this localization prevents a surfack closure is intense $(\mathrm{e} . \mathrm{g}$ for the under-aged and peak-aged alloys, and $R=0.1$ ).

The described as Type II and the associated crack The detion can be described as a tearing of a plastic zone wing may be interpreted in terms of cumulated plastic strains. In the hyper overaged alloy where the hardening precipitates cannot be sheared by dislocations, the slips distribution is relatively homogeneous, the straine material can be thus considered as isotropic and tears where the strain is the highest. The crack advances by successive leaps, the amplitude of wht be can get down to $5 \mu \mathrm{m}$. When the crack is stopped, a new plastic zotic strain created before it propagates again. Such a cumulated plastic strain criterium is in accordance with the ductile fractographic aspect of crack hyper-overaged alloy (Lafarie-Frenot, 1983). The mean path low surfaces remains perpendicular to the loading axis, which leads to to very low, roughness. The closure concerns long crack lengths and all along the crack

close to zero, residual spacing between the crack
in the hyper-overaged alloy fatigued at $R=0.1$.

When the age-hardening condition leads to intermediate and transitional When the age-hardening condition mechanisms of fracture down to the thres intensity amplitude and load ratio. varying with the values of the stress irack Thus, the residual spacing along the (i.e evolution along the crack), by the crack surfaces roughes and load ratio. In peak-aged allo $R=0.5$ is explained by the high the crack tip, bs surfaces roughness observe higher residual stresses spacing values near at $R=0.1$ 
2048

There is a good qualitative agreement between the amount of crack surfaces roughness and crack edges spacing observed in almost every case. However it is not true for the of residual spacing. The closure point at $a=23 \mathrm{~mm}$ corresponds to the crack length for zones size, were the highest during this test. This observation points out zhat the lo ling history by the wake of residual strain left behind the crack tip has a great influence on the amount of crack closure, when the crack tip displacement is small, e.g. at near-threshold level. That explains that, during a test with a decreasing stress amplitude, one observes an increasing amount of crack closure when the crack tip displacement becomes of the order of the crack surfaces roughness (Lafarie-Frenot, 1983). Furthermore, the plastic elongation along the crack is more important near the notch and induces preferentially crack closure in this region, especially when the crack surfaces roughness is low along the whole crack.

CONCLUSIONS

i - Fatigue tests conducted in vacuum on a 7075 Al alloy have permitted to characterize two types of plastic deformation and fracture mode which depend on the heat-treatment.

- in the under-aged alloy, fracture by shearing along slip planes leads to high values of crack surfaces roughness. In such a case, the crack closes only at acute angles and where the crack path is

close to the loading axis.

- in the hyper-overaged one, fracture by tearing a plastic zone wing induces a very flat aspect of the crack, particularly near the

threshold. The closure then concerns long lengths of the crack.

ii - The localization and the amount of crack closure much depends on the crack surfaces roughness evolution during the test and the loading history (i.e. froad ratio and plastic elongation

REFERENCES

DAVIDSON, D.L., (1981), Incorporating threshold and environmental ef fects into damage accumulation model for fatigue crack growth. Fatigue of Engng. Mater, and Str. $3,229$.

ELBER, W., (1970), Fatigue crack closure under cyclic tension.

Engng Fr. Mech. 2, 37.

GRANVILLE SEWELL, MARCUS H.L., (1977), A model for fatigue crack closure based on surface roughness and residual strain. Scripta Met. 11, 521. AFARIE-FRENOT, M.C., GASC, C., (1983), The influence of age-hardening

on fatigue crack propagation behaviour in 7075 Aluminium alloy in

vacuum. To be published in Fatigue of Engng. Mater and Str.
MINAKAWA, K., MCEVILY, A.J., (1981), On crack closure in the near threshold region. Scripta Met. $15,633$.

RANGANATHAN, N., PETIT, J.,(1983), Quantitative measurements in the plas tic zone created by a single overload in air and vacuum. ASTM, STP 811

SURESH, S., RITCHIE, R.0., (1982), A geometrical model for fatigue

crack closure induced by surface roughness. Metal. Trans. 13A, 1627 